\title{
Functional Outcome of Treatment of Fracture Shaft Femur in Children Using Titanium Elastic Nails System
}

\author{
Balkrishan Agarwal ${ }^{1}$, Ramesh Chand Jindal², Manjeet Singh ${ }^{3}$, Harinder Singh Sandhu \\ ${ }^{1}$ Department of Orthopaedics, Maharishi Markandeshwara (Deemed to be University) Mullana, Ambala, \\ Haryana, India. ${ }^{2}$ Department of Orthopaedics, Maharishi Markandeshwara (Deemed to be University) \\ Mullana, Ambala, Haryana, India. ${ }^{3}$ Department of Orthopaedics, Maharishi Markandeshwara (Deemed to \\ be University) Mullana, Ambala, Haryana, India. ${ }^{4}$ Department of Orthopaedics, Maharishi \\ Markandeshwara (Deemed to be University) Mullana, Ambala, Haryana, India.
}

\section{ABSTRACT}

\section{BACKGROUND}

Fractures of the femur are the most incapacitating fractures. For children aged 6-16 years, there is no clear consensus as to the preferred treatment. The conventional treatment of traction and casting is no longer preferred. We report our experience in titanium elastic nailing for treatment of paediatric femoral diaphyseal fractures. We wanted to study the functional outcome following the use of flexible titanium nails for femoral shaft fractures in children and evaluate the duration of union in the abovementioned fractures. We also wanted to study the complications of fracture shaft femoral after intramedullary nailing.

\section{METHODS}

Thirty patients in the age group of 6-16 years with displaced diaphyseal femoral fractures were stabilized with titanium elastic nails. Patients were followed up clinically and radiologically for a minimum period of 6 months to 1 year. The final results were evaluated using Flynn's criteria. Technical difficulties and complications associated with the procedure were also analysed.

\section{RESULTS}

Overall results were excellent in 28 cases and satisfactory in 02 cases. No patient had poor result. The average hospital stay was 6.47 days. All the fractures healed in 70 days (10 weeks) of times with an average time of union of 60 days ( 7.5 weeks). The most common complication encountered was soft tissue irritation at the nail entry site seen in 2 cases. Clinically, shortening was noticed in 3 cases, while no patient had lengthening. Malalignment was seen in only 6 cases. There was no iatrogenic bone injury, delayed injury and non-union, bending or breaking of implant, refracture and avascular necrosis of femoral head. There was no evidence of physeal injury on follow up.

\section{CONCLUSIONS}

Titanium elastic nails are a relatively easy to use, minimally invasive, physealprotective implant system with high rate of good and excellent outcomes in children aged 6-16 years. Technical pitfalls can be eliminated by adhering to the basic principles.
Corresponding Author: Dr. Ramesh Chand Jindal, Department of Orthopaedics, MMIMSR, Mullana, Ambala, Haryana, India.

E-mail: drbalkrishan122@gmail.com

DOI: $10.14260 /$ jemds/2020/102

Financial or Other Competing Interests: None.

How to Cite This Article:

Agarwal B, Jindal RC, Singh $M$, et al. Functional outcome of treatment of fracture shaft femur in children using titanium elastic nails system. J. Evolution Med. Dent. Sci. 2020;9(07):453-457, DOI: 10.14260/jemds/2020/102

Submission 15-12-2019,

Peer Review 21-01-2020,

Acceptance 30-01-2020,

Published 17-02-2020.

\section{KEY WORDS}

Titanium, Nails, Fractures, Bone, Femur, Paediatrics 


\section{BACKGROUND}

Fractures of the femur are the most incapacitating fractures in children. They account for approximately $1.6 \%$ of all bony injuries in children. ${ }^{1}$ these fractures have bimodal age distribution with peak at 6 and 16 years. Fractures are mostly caused by fall during play (30\%) or abuse. Low velocity trauma leads to transverse fractures and high-speed causes comminuted or segmental fractures. ${ }^{2}$ Femoral shaft fractures are demanding and disabling injuries both for the patient and the family. Method of treating pediatrics diaphyseal femur fractures are dictate by patient age, fracture characteristics, associated bone and soft tissue injuries and also family socioeconomics status as well. What constitutes appropriate management of femoral shaft fractures in children is a subject of much debate. Treatment ranges from strictly nonsurgical methods (e.g. closed reduction with hip Spica casting or traction followed by casting) to surgical stabilization (using flexible intramedullary nailing, rigid trochanteric entry nailing, external fixation or sub muscular compression plating and screws) ${ }^{3}$ Nonsurgical management has been the standard care most children historically but disadvantages of this treatment include prolonged immobilization and necessitate long hospital stay. Casting with or without traction is still accepted treatment for treatment for isolated femur fracture in children of preschool age below age 16 years. ${ }^{4}$

The management of pediatrics femoral shaft fractures has gradually evolved towards a more operative approach in past two decades. This is because of need for healthcare cost containment and a desire for more rapid mobilization recovery and early discharge of the patient to home and reintegration with the parents and family. This is also a recognition that prolonged immobilization can have negative effects even on children. Hence these factors have been more and more considered as important in treatment of fractures shaft of femur in children. The treatment for children between the ages 6 and 16 years is still controversial. Many such patients may be treated successfully with immediate closed reduction and hip Spica casts or traction. However, in present time's external fixation compression plating or rigid or flexible intramedullary nail fixation are being used more frequently, particularly in patients with multiple trauma.

Fractures of the femoral shaft in children have been traditionally treated by immobilization in a Spica cast, either immediately or after a period of traction. Surgical treatment is limited to open fracture or patient with head injury or multiple injuries. Conservative treatment necessitates a long stay in hospital for traction and subsequent immobilization in an uncomfortable cast. ${ }^{2}$ This treatment is not well tolerated specially in adolescence. Moreover, near the end of growth, accurate reduction is necessary as malunion is no longer correctable by bony maturation. There is little disagreement regarding the treatment of younger children (usually less than 6 years of age) and adults ( $>16$ years). For children aged between 6- 16 years, there are wide varieties of surgical and nonsurgical treatment options available with no clear consensus as to the preferred treatment. ${ }^{5} \mathrm{~A}$ systematic review of the literature provides little evidence to sup-port one method of treatment over another. Compared with younger children, patients in this intermediate age group have a higher risk of shortening and malunion when early closed reduction and a Spica cast is used ${ }^{3}$. Operative treatment results in short hospitalization and early mobilization, which has psychological, social, educational and economic advantages over conservative treatment. Considering the low level of evidence in studies supporting treatment with titanium elastic nails, and their widespread use, we initiated a prospective study in children between the age group of 6-16 years presenting with femoral shaft fractures in orthopedic emergency.

We wanted to study the functional outcome following the use of TENS (titanium elastic nailing system) for fracture shaft of femur in children. We also wanted to study the duration of union and complications of fracture shaft femoral after treatment with TENS.

\section{METHODS}

This is a prospective study carried out to evaluate the outcome, time taken for union of fracture and complication with use of TENS. Ethical committee clearance was obtained before commencing the study. Thirty consecutive patients of fracture shaft femur in children between 6-16 years admitted in MMIMSR, Mullana, Ambala were considered for the study. All patients were taken up surgery within seven days of their injury. Informed consent was taken from all patients. Patient selected on basis according to inclusion and exclusion criteria as under.

\section{Inclusion Criteria}

1. Simple/closed fracture shaft of femur.

2. Age 6 to 16 years.

3. Both male and female.

4. Patient willing for operative procedure.

\section{Exclusion criteria}

1. Age below 6 years to above 16 years

2. Compound fracture

3. Pathological fracture

4. Fracture near metaphysis.

5. Other associated fracture.

These nails are pre-curved to an angle of 30 -45 degrees. The apex of the curvature of the nails should be at the level of the fracture site to ensure a good equilibrium of reduction and stabilization forces ${ }^{6}$. Nails were prepared by bending them at 45 degrees about $2 \mathrm{~cm}$ from proximal end to facilitate its entry into the medullary canal and also to allow the nail to bounce off the opposite cortex at the time of insertion. Under general anaesthesia, the patient was placed on a fracture table in supine position with or without traction boots depending upon whether reduction could be accomplished with manual traction or not. Image intensifier was positioned on the contralateral side of the affected femur. The set up allowed the surgeon to access both medial and lateral aspects of the distal femur. Fracture was reduced and alignment confirmed under C ARM image intensifier in both AP and lateral views an incision was made on the lateral side of thigh $2.5 \mathrm{~cm}$ above the distal physis and extending proximally for $1-2 \mathrm{cms}$. Drill bit size higher than the selected diameter, nail along with drill sleeve (to protect soft tissues) was used to make cortical hole. Drill bit was kept perpendicular to bone for penetration. A 
curved bone awl, at angle of $\sim 45$ degree to the cortex was used to enlarge the hole. Both the nails of the selected size were inserted through entry points one after the other. Under image intensifier control, each nail was driven with a Thandle by rotatory movement up to the fracture site. By rotation movements of the T-handle with or without limb manipulation, the nail was advanced about $2 \mathrm{~cm}$ into the proximal fragment with convexity of nail glancing off from the opposite cortex. At the same time the second nail was similarly advanced to enter the proximal fragment and in the meantime any traction was released to avoid any distraction. The Ist nail was not advanced so far till the other nail crossed the fracture site. Any deformity was corrected by altering the position of the nails. The two-nail construct was kept in a symmetrical alignment face to face with the maximum curvature of the nails at the level of the fracture. In cases which required open reduction, a 3-5 $\mathrm{cm}$ incision was used at the fracture site on lateral aspect for manipulation of the fracture alignment. Distally the nails were cut leaving only 1-2 $\mathrm{cm}$ outside the cortex. The extra osseous portion of the nails was slightly bent away from the bone to facilitate removal later on. In all cases same diameter nails were used with aim to make 3-point stable fixation. Wound was closed in layers and aseptic dressing was done.

\section{RESULTS}

Age of patients was between 7 to 15 years with mean of 11.3 years. Male patients were double the number of females. Right femur was more frequently involve and pattern of fracture was predominantly transverse $60 \%$. Mean hospital stay was 6.47 days with a range of 5-7 days. Time between injury and operation was between 5 to 7 days and mean of 7.73 days. In all patient active and passive movement was possible 3 weeks. Partial weight bearing was started after 3 weeks and full weight bearing was possible after union in maximum of 10 weeks' time. Bridging callus at least three cortices was first noted on follow-up radiograph at an average of 3 weeks at which time partial weight bearing was started. Majority of the patients (25) achieved union by 6 weeks with average time to union being after 10 weeks and at this time full weight bearing was started. Majority of the patients (20) achieved full range of knee motion up to 12 weeks. Three cases had terminal restriction of knee flexion $\left(20^{\circ}-30^{\circ}\right)$, which improved after nail removal. Results were evaluated using Flynn's ${ }^{7}$ criteria and was seen excellent in 28 (93.33\%) cases, while it was satisfactory in $02(6.66 \%)$ cases. No patient had poor result. The results were excellent in $60 \%$ of the transverse fractures followed by $36.66 \%$ of the oblique fractures and $3.34 \%$ of the spiral fractures. Two case was soft tissue irritation other complication limb length discrepancy in 3 cases is not significant and is excellent category as per Flynn criteria. Angulation was seen in only 8 cases and no one had more than 10 degrees of angulation.

\begin{tabular}{|c|c|c|}
\hline Time to Union (Weeks) & No. of Cases & Percentage \\
\hline 7 weeks & 8 & $26.7 \%$ \\
\hline 8 weeks & 17 & $56.7 \%$ \\
\hline 9 weeks & 4 & $13.3 \%$ \\
\hline 10 weeks & 1 & $3.3 \%$ \\
\hline Total & $\mathbf{3 0}$ & $\mathbf{1 0 0 . 0 \%}$ \\
\hline \multicolumn{2}{|c|}{ Table 1. Distribution of Time Taken for Union } \\
\hline
\end{tabular}

\begin{tabular}{|c|c|c|}
\hline Follow Up (Weeks) & No. of Cases & Percentage \\
\hline 20 weeks & 5 & $16.7 \%$ \\
\hline 22 weeks & 2 & $6.7 \%$ \\
\hline 24 weeks & 23 & $76.7 \%$ \\
\hline Total & $\mathbf{3 0}$ & $\mathbf{1 0 0 . 0 \%}$ \\
\hline Table 2. Distribution of Time Taken for Full Weight Bearing
\end{tabular}

\begin{tabular}{|c|c|c|}
\hline Radiological Malalignment & No. of Cases & Percentage \\
\hline 0 & 22 & $73.3 \%$ \\
\hline 10 Sagittal & 3 & $10.0 \%$ \\
\hline 15 Sagittal & 1 & $3.3 \%$ \\
\hline 5 Coronal & 4 & $13.3 \%$ \\
\hline Total & $\mathbf{3 0}$ & $\mathbf{1 0 0 . 0} \%$ \\
\hline \multicolumn{2}{|c|}{ Rable 3. Distribution of Study Participants According to } \\
\hline
\end{tabular}

\section{DISCUSSION}

Until recently, skeletal traction and application of a Plaster of Paris cast are the preferred method for treatment of diaphyseal femoral fractures in children and young adolescents. ${ }^{8}$ However, orthopedics have tried a variety of methods to avoid prolonged immobilization and provide better nursing care. Recent studies have also increased our awareness of the psychosocial and economic effects of Spica cast immobilization on children and their families. ${ }^{9,10}$ In recent years, perhaps the best results have been achieved by flexible intramedullary nailing. Titanium elastic nail with its newer design and better material seems advantageous over other surgical methods particularly in this age group because it is a load sharing internal splint that does not violate physes, allows early mobilization and maintains alignment.

\section{Hospitalization Stay}

In our study average hospitalization time was 6.47 days. This is significantly less than average of 28 days reported by Herndon et al 11 showed that the hospital stay in the nonsurgical group averaged 28 days. This was much higher than reported in the study by Ann Ho et al ${ }^{12}$ (5.3 days) and Heybeli et al 13 (5.5 days). However, the results were similar to other studies conducted in Indian setup by Saikia et al ${ }^{14}$ (9.8 days) and in the surgical group averaged 17 days, which was significant. Flynn et $\mathrm{al}^{7}$ reported that compared with children treated with traction and cast, those treated with titanium elastic nails had shorter hospitalization, walked early. 


\section{Union}

In the present study, bridging callus was first noted on follow-up radiographs at an average of 4.53 weeks. This is similar to the study conducted by Flynn et $\mathrm{al}^{7}$ ( 4 weeks) but significantly more than 3 weeks reported by Cramer et al ${ }^{15}$ ( 3 weeks) our study averaged 7.73 weeks. It was only then the patients were started on full weight bearing. As reported by Flynn et al, ${ }^{7}$ Cramer et al,15 Mann et al ${ }^{16}$ and Galpin et al, in our study too there was no case of delayed and nonunion.

\section{Full Range of Motion}

In our study, majority of the patients achieved full range of knee motion by 3 weeks. The patients were typically taught a home exercise program including a range of motion exercises, hip abductor and knee extensor strengthening exercises during the perioperative period. Similar findings were noted in the study con ducted by Bar-On et $\mathrm{al}^{2}$ and Cramer et al ${ }^{15}$

In our study on functional outcome and complications of treatment of fracture shaft femur with Titanium Elastic Nailing System, youngest patient was 7 yr. old \& the oldest was 15 yr. old with a mean age of 11.3 yrs. Male: female ratio was (2:1). Most common mode of injury was roadside accident followed by fall from height or while playing and due to slipping. Most common pattern of fracture was transverse. Most common side involved was right. Most of the patients were operated with in week time after injury and 2 days after admission and required hospitalization for 5-7 days with mean 6.47 days. Joint movement started on $2^{\text {nd }}$ post-operative were possible to full extent at 3 week time and were painless. All patient started partial weight bearing after 3 weeks and full weight bearing after 10 weeks. Angulation of $5^{\circ}-10^{\circ}$ was seen in 4 patients was not clinically significance same was true about LLD which was between 5$10 \mathrm{~mm}$, shortening. There was no deep infection, superficial infection in few patients resolved without any intervention. There was no disturbance in physeal growth or vascularity of head of femur.

\section{Complication}

In our study LLD (shortening) of $5 \mathrm{~mm}$ in 2 cases and $10 \mathrm{~mm}$ in one case was not clinically significantly an is in excellent category as per Flynn criteria. Malalignment was seen in patients in our study and no patient had more than 10 degrees of angulation. In the remaining 3 cases, apex of the curvature was not at the fracture site resulting in malalignment. Herndon et al ${ }^{17}$ reported malunion in 7 of 24 patients treated with traction no malunion was observed in 21 children treated using TENS nailing. Intraoperative difficulties encountered in our study were failure of closed reduction seen in 5 cases mainly because they were operated late (after one week of injury) and soft tissue interposition seen in one case.

\section{CONCLUSIONS}

In children between 6 years and 16 years of age, Titanium Elastic Nailing System is a good alternate method of treatment: It offers the following advantages over conservative treatment-
- Early joint mobilization.

- Less period of hospitalization and bed restriction.

- Early weight bearing both partial and complete.

- Insignificant LLD and angulation deformity or bone infection.

There is added advantage of better patient and attendant satisfaction, due to psychological, social, educational and economic factors. There is no or very little risk of physeal growth disturbance or avascular necrosis head of femur.

\section{REFERENCES}

[1] Kasser JR, Beaty JH. Femoral shaft fractures. In: Beaty JH, Kasser JR, eds. Rockwood and Wilkins fractures in children. $6^{\text {th }}$ edn. New York: Lippincott Williams and Wilkins 2006: p. 893.

[2] Bar-On E, Sagiv S, Porat S. External fixation or flexible intramedullary nailing for femoral shaft fracture in children. A prospective, randomised study. J Bone Joint Surg Br 1997;79(6):975-8.

[3] Clinkscales CM, Peterson HA. Isolated closed diaphyseal fractures of the femur in children: comparison of effectiveness and cost of several treatment methods. Orthpaedics 1997;20(12):1131-6.

[4] Martinez AG, Carroll NC, Sarwark JF, et al. Femoral shaft fractures in children treated with early spica cast. J Paediatr Orthop 1991;11(6):712-6.

[5] Metaizeau JP. Stable elastic intramedullary nailing for fractures of the femur in children. J Bone Joint Surg Br 2004;86(7):954-7.

[6] Mazda K, Khairouni A, Pennecot GF, et al. Closed flexible intramedullary nailing of the femoral shaft fractures in children. J Paediatr Orthop B 1997;6(3):198-202.

[7] Flynn JM, Hresko T, Reynolds RA, et al. Titanium elastic nails for paediatric femur fractures: a multicenter study of early results with analysis of complications. J Paed Orthop 2001;21(1):4-8.

[8] Flynn JM, Skaggs DL, Sponseller PD, et al. The surgical management of paediatric fractures of the lower extremity. Instr Course Lect 2003;52:647-59.

[9] Reeves RB, Ballard RI, Hughes JL. Internal fixation versus traction and casting of adolescent femoral shaft fractures. J Paediatr Orthop 1990;10(5):592-5.

[10] Hughes BF, Sponseller PD, Thompson JD. Paediatric femur fractures: effect of Spica cast treatment on family and community. J Paediatr Orthop 1995;15(4):457-60.

[11] Herndon WA, Mahnken RF, Yngve DA, et al. Management of femoral shaft fractures in the adolescent. J Paediatr Orthop 1989;9(1):29-32.

[12] Ann Ho C, Skaggs DL, Tang CW, et al. Use of flexible intramedullary nails in paediatric femur fractures. J Paediatr Orthop 2006;26(4):497-504.

[13] Heybeli M, Muratli HH, Celebi L, et al. The results of intramedullary fixation with titanium elastic nails in children with femoral fractures. Acta Orthop Traumatol Turc 2004;38(3):178-87. 
[14] Saikia KC, Bhuyan SK, Bhattacharya TD, et al. Titanium elastic nailing in femoral diaphyseal fractures of children in 6-16 years of age. Indian J Orthop 2007;41(4):381-5.

[15] Salem KH, Lindemann I, Keppler P. Flexible intramedullary nailing in paediatric lower limb fractures. J Paediatr Orthop 2006;26(4):505-9.
[16] Mann DC, Weddington J, Davenport K. Closed Ender nailing of femoral shaft fractures in adolescents. J Paediatr Orthop 1986;6(6):651-5. 